\title{
Effects of Inhibitors of Sterol Synthesis on Growth of Sordaria and Phytophthora
}

\author{
By C. G. ELLIOTT \\ Botany Department, University of Glasgow, Glasgow W.2
}

(Accepted for publication I7 February 1969)

SUMMARY

Four hypocholesteremic compounds, SKF 330I-A, SKF 525-A, SKF I6467-A and AY 9944, inhibited the growth of Sordaria fimicola; SKF 23I4, SKF $7732-\mathrm{A}_{3}$ and SKF $7997-\mathrm{A}_{3}$ did not. All seven compounds inhibited the growth of Phytophthora cactorum. The inhibition of growth of $S$. fimicola by SKF 330I-A and AY 9944 was annulled by certain unsaturated fatty acids but not by sterols; with $P$. cactorum the inhibition was annulled by oleic acid + cholesterol.

With Sordaria fimicola sub-inhibitory concentrations of SKF 330I-A caused growth which showed two phases, distinguished by an abrupt change in growth rate. At the position of the hyphal front when growth rate changed a ring of perithecia was formed. During the second period, when growth was slower, perithecia were formed in rings. The number of perithecia formed could be at least twice that in the drug-free controls. With AY 9944 no perithecia were produced at concentrations sub-inhibitory to vegetative growth. On media with SKF 330 I-A or AY 9944 and oleic acid, few perithecia were formed despite good vegetative growth; with SKF 330 I-A, but not AY 9944, the addition of cholesterol as well increased perithecial production.

\section{INTRODUCTION}

Sterols have been shown to be required for sexual reproduction in the oomycetes (Hendrix, 1964; Haskins, Tulloch \& Micetich, 1964; Elliott, Hendrie, Knights \& Parker, 1964; Leal, Friend \& Holliday, 1964), and they are also required for the production of normal sporangia and zoospores (Chee \& Turner, 1965; Hendrix, 1965). Sterols do not appear to be essential for vegetative growth, which can take place in sterol-free medium, although these fungi appear not to synthesize them (Elliott et al. 1964; Hendrix, 1966; Schlosser \& Gottlieb, 1966). The role of sterols in their metabolism can thus be studied simply by adding the sterol to the medium.

The higher fungi, however, synthesize sterols, and it was thought that some indication of the function of sterols here might be obtained by the use of compounds which inhibit sterol synthesis (hypocholesteremic compounds). If sterols have a specific role in reproduction, these compounds would perhaps have different effects on vegetative and reproductive growth. The ascomycete Sordaria fimicola was chosen for such an investigation. It is homothallic and forms perithecia readily but has no asexual spores; thus attention is more readily directed to effects on sexual stages. It was confirmed that this organism synthesizes sterols (B. A. Knights \& C. G. Elliott, unpublished 
observations). The effect of the compounds on the oomycete Phytophthora cactorum was studied for comparison.

The hypocholesteremic compounds tested were $\beta$-diethylaminoethyl-diphenylpropyl acetate hydrochloride (SKF 525-A); 2,2-diphenyl-I-( $\beta$-dimethylaminoethoxy)pentane hydrochloride (SKF 33OI-A); 2,2-diphenyl-pentanoic acid (SKF 23I4);<smiles>CCCC(C(=O)O)(c1ccccc1)c1ccccc1</smiles>

SKF 2314

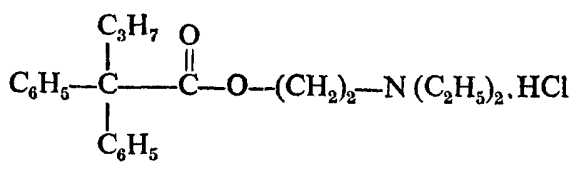

SKF 525-A

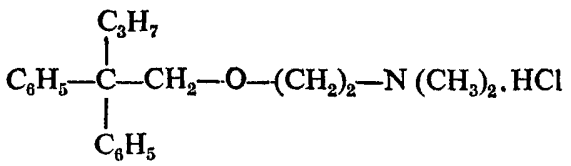

SKF 3301-A

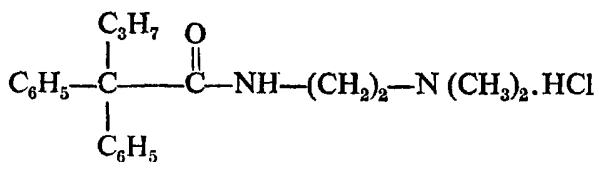

SKF 16467-A

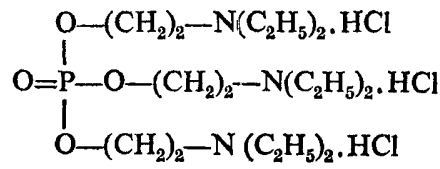

SKF 7997-A<smiles>Clc1cccc(CNCc2ccc(CNCc3ccccc3Cl)cc2)c1</smiles>

Fig. I. Structure of hypocholesteremic compounds tested.

$\mathrm{N}$-dimethylaminoethyl- $\alpha, \alpha$-diphenyl valeramide hydrochloride (SKF I6467-A); tris(2-dimethylaminoethyl)-phosphate trihydrochloride (SKF 7732- $\mathrm{A}_{3}$ ) and its diethyl analogue (SKF 7997- $\mathrm{A}_{3}$ ); trans-I,4-bis(2-chlorobenzylaminoethyl)cyclohexane dihydrochloride (AY 9944). The structure of these compounds is shown in Fig. I. Work on mammalian tissue has shown that SKF 525-A and SKF 330I-A act before the formation of squalene (Holmes \& Bentz, I960; Holmes \& Di Tullio, I962). SKF 
7732- $\mathrm{A}_{3}$ and SKF 7997- $\mathrm{A}_{3}$ principally inhibit the conversion of lanosterol to zymosterol (Holmes \& Di Tullio, 1962). AY 9944 inhibits the saturation of the double bond at position 7; 7-dehydrocholesterol cannot be converted to cholesterol (Chappel et al. I964; Horlick, 1966). It has also been shown that SKF 7997- $A_{3}$ inhibits sterol synthesis in the flowering plant Xanthium pensylvanicum (Bonner, Heftmann \& Zeevaart, I963).

\section{METHODS}

Fungi. The strain of Sordaria fimicola used was obtained from Professor C. T. Ingold, Birkbeck College, London. The strain of Phytophthora cactorum was IMI 2 I I68, obtained from the Commonwealth Mycological Institute, Kew.

Media. Sordaria fimicola was grown on a medium containing: glucose, $2.5 \mathrm{~g}$.; $\mathrm{NaNO}_{3}, \mathrm{I} \cdot 0 \mathrm{~g}$. $\mathrm{KH}_{2} \mathrm{PO}_{4}, 0.5 \mathrm{~g}$.; $\mathrm{MgSO}_{4} \cdot 7 \mathrm{H}_{2} \mathrm{O}, 0.25 \mathrm{~g}$.; trace element solution, I ml.; thiamine hydrocholoride, $2 \mathrm{mg}$.; biotin, $4 \mu \mathrm{g}$.; water, I 1 . Phytophthora cactorum was grown on a medium containing: sucrose, Io g.; L-asparagine, I $\cdot 0$ g.; $\mathrm{K}_{2} \mathrm{HPO}_{4}$, $0.5 \mathrm{~g}$.; $\mathrm{MgSO}_{4} .7 \mathrm{H}_{2} \mathrm{O}, 0.25 \mathrm{~g}$.; trace element solution, I ml.; thiamine hydrochloride, I mg.; water, I l. The trace element solution contained: $\mathrm{Na}_{2} \mathrm{~B}_{4} \mathrm{O}_{7}$. I० $\mathrm{H}_{2} \mathrm{O}, 88 \mathrm{mg}$; $\mathrm{CuSO}_{4} \cdot 5 \mathrm{H}_{2} \mathrm{O}, 393 \mathrm{mg}$.; $\mathrm{Fe}_{2}\left(\mathrm{SO}_{4}\right)_{3} .9 \mathrm{H}_{2} \mathrm{O}$, 9IO mg.; $\mathrm{MnCl}_{2} .4 \mathrm{H}_{2} \mathrm{O}, 72 \mathrm{mg}$.; $\mathrm{Na}_{2}$ $\mathrm{MoO}_{4} .2 \mathrm{H}_{2} \mathrm{O}$, $50 \mathrm{mg}$.; $\mathrm{ZnSO}_{4} \cdot 7 \mathrm{H}_{2} \mathrm{O}, 4403 \mathrm{mg}$.; ethylenediaminetetraacetic acid disodium salt, $5 \mathrm{~g}$; water, I 1 . Difco Bacto-agar $(\mathrm{I} \%$, w/v) was used to solidify the media.

The hypocholesteremic compounds were dissolved in sterile water; SKF 23 I 4 was dissolved in $\mathrm{O} \cdot \mathrm{I} \mathrm{M}-\mathrm{NaOH}$. Sterols and fatty acids were dissolved in diethyl ether. These substances were added to the medium after it was autoclaved and while still hot.

Both fungi were grown at $24^{\circ}$ in the dark in $9 \mathrm{~cm}$. diameter Petri dishes containing $\mathrm{I} 6 \mathrm{ml}$. medium. The inoculum was a disc $5 \mathrm{~mm}$. diameter cut from mycelium growing on drug-free medium. Growth was usually measured as colony diameter; in some experiments the weight of mycelium was also determined by melting down the agar cultures in an autoclave, rinsing the mycelium in hot water and drying (Timnick, Lilly \& Barnett, 195I). Perithecia were counted in two opposite sectors (occasionally four) of about 23 angular degrees in each Petri dish.

\section{RESULTS}

\section{Observations on Sordaria fimicola}

Compound $S K F$ 330I-A. When an inoculum disc cut from growth on drug-free medium was placed on medium containing SKF 330I-A, the hyphae after the initial lag phase grew at a constant rate for some $40 \mathrm{hr}$ (Fig. 2), during which period the growth rate was related to drug concentration, but then the growth rate rather abruptly changed and growth continued at a constant but much slower rate (Fig. 2). (A slight change in growth rate occurred also in the controls at about the same time in many experiments.)

Perithecia were mature in the controls in 7 days and were more or less evenly distributed over most of the Petri dish (Pl. I, fig. I). At 7 days, the colonies on media with SKF 330I-A $20 \mathrm{mg}$./1. or more did not fill the Petri dish, but at this time they bore perithecia densely crowded in a ring towards the outer part of the colony. With further incubation more perithecia were formed during the continued slow growth, 
and these perithecia were distributed in definite rings. At $20 \mathrm{mg} . / \mathrm{l}$. the innermost ring was sharply defined, those beyond less so ( $\mathrm{Pl}$. I, fig. 2), but the rings became more sharply defined with increasing concentration of the drug up to $50 \mathrm{mg}$./1. (Pl. I, fig. 5). The distance between successive rings corresponded to about 3 days growth. The innermost ring was formed at the position of the hyphal front at the time of abrupt change in growth rate. The perithecia were so densely crowded in the innermost ring that even at 7 days the greatest numbers of perithecia per Petri dish were found not in the controls but in media with SKF $330 \mathrm{I}-\mathrm{A} 20 \mathrm{mg} . / \mathrm{l}$. (Table I). With continued perithecial production during the slow growth on drug-containing media, the numbers of perithecia continued to increase, as shown in Table I. At high concentrations of SKF 330I-A (e.g. $70 \mathrm{mg}$./1.) very few perithecia were formed, but the fungus produced a considerable amount of brown pigment. No growth from the inoculum disc occurred at SKF $330 \mathrm{I}-\mathrm{A}$ I $20 \mathrm{mg}$./1.

Table I. Sordaria fimicola. Counts of perithecia in media with SKF 330I-A; means of two counts in each of six Petri dishes, the same dishes being counted on two occasions

\begin{tabular}{|c|c|c|}
\hline \multirow{2}{*}{$\begin{array}{c}\text { Concentration } \\
\text { of SKF 330I-A } \\
\text { mg/l. }\end{array}$} & \multicolumn{2}{|c|}{ Age of culture (days from inoculation) } \\
\hline & 7 & 19 \\
\hline 0 & $63 \pm 4 \cdot 0$ & $86 \pm 5 \cdot 0$ \\
\hline 10 & $79 \pm 8 \cdot 5$ & $99 \pm 7 \cdot 2$ \\
\hline 20 & $8 I \pm 9 \cdot 7$ & $158 \pm 9 \cdot 1$ \\
\hline 40 & $55 \pm 6 \cdot 9$ & $149 \pm 13 \cdot 8$ \\
\hline 60 & $9 \pm 3.9$ & $26 \pm 5 \cdot 3$ \\
\hline
\end{tabular}

Compound SKF 525-A. The growth curves of Sordaria fimicola on media with various concentrations of this compound resembled those of Fig. 2, but the change of growth rate after the initial more rapid phase was not so marked. The effect of concentration of the compound on the initial growth rate is shown in Fig. 3. Growth rate did not fall off continuously with increasing concentration. The break in the curve (Fig. 3) corresponded to a change in the appearance of the margin of the colony. At $40 \mathrm{mg}$. $/ 1$. and above the main hyphae continued to elongate for a considerable time, but the growth became progessively more and more diffuse, the hyphae being sparsely branched and widely spaced. At 30 and $20 \mathrm{mg}$./l., the edge of the colony was much more definite.

At $50 \mathrm{mg}$./1. only very small perithecial primordia were seen, and they were few and well scattered. At $40 \mathrm{mg} . / 1$. the perithecia were more numerous, but they reached a maximum diameter of in most dishes of about $150 \mu$ (normal size in the controls 300 to $350 \mu$ ) and ostioles were not developed. (Some mature perithecia were, however, found in a few of the dishes in each experiment.) The perithecia and primordia occurred in more or less definite rings, but the rings were less clearly defined than with SKF $330 \mathrm{r}-\mathrm{A}$. At 30 and $20 \mathrm{mg}$./1. numerous perithecia matured; there were also many smaller immature perithecia which reached a later stage of development than the abortive perithecial initials in the controls. The number of mature perithecia at these concentrations was also greater than in the controls.

Compound SKF 16467-A. The inhibitory concentrations of this compound were 
considerably higher than with SKF $330 \mathrm{I}-\mathrm{A}$ and $525-\mathrm{A}$, as shown in Fig. 3. As with 330I-A, there was an abrupt change in growth rate with subinhibitory concentrations (e.g. $75 \mathrm{mg}$./1.) when the mycelium had covered about half the Petri dish, and perithecia were produced in a definite ring. Beyond this ring perithecia were scattered, rather

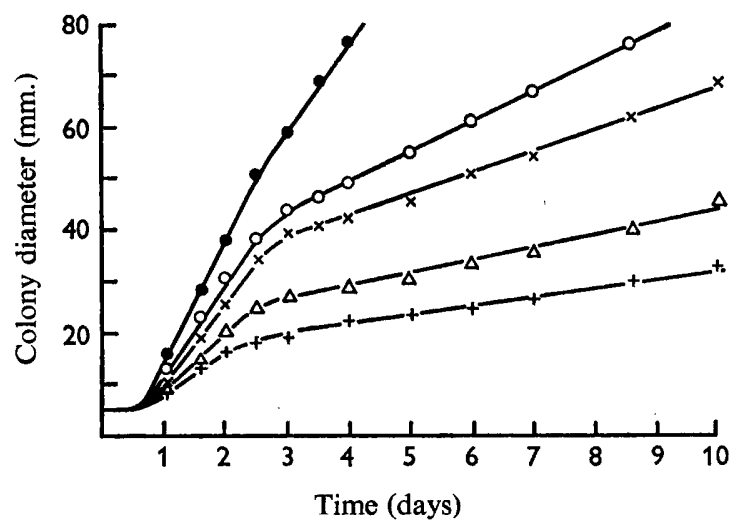

Fig. 2. Growth of Sordaria fimicola in media with various concentrations of SKF 330I-A. $\longrightarrow-0$ mg./l.; $\bigcirc-0,20 \mathrm{mg} . / 1 . ; \times-\times, 30 \mathrm{mg} . / 1$; $\triangle-\triangle, 50 \mathrm{mg} . / 1 . ;+-+, 70 \mathrm{mg}$./l.

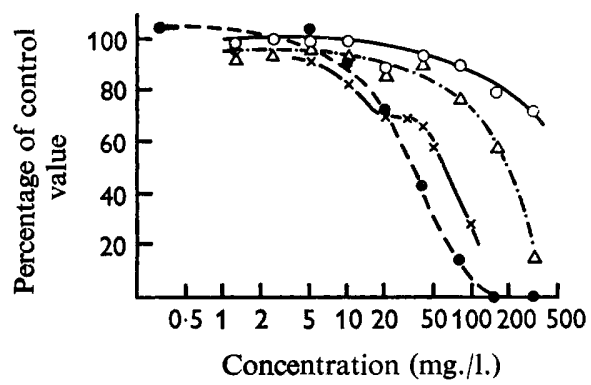

Fig. 3

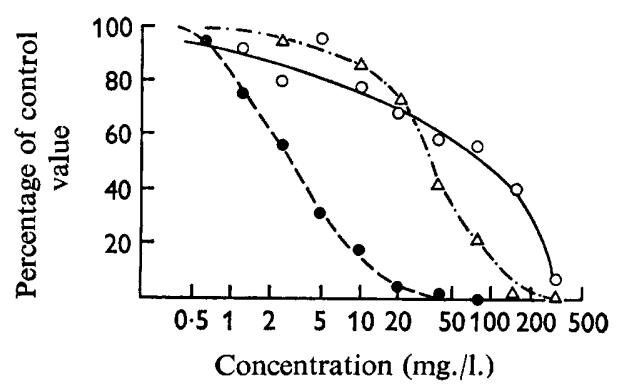

Fig. 4

Fig. 3. Effect on initial linear growth rate of Sordaria fimicola hyphae of varying concentrations of hypocholesteremic compounds. O-O, SKF $2314 ; \triangle-\cdot-\triangle$, SKF I6467-A; $\times-x$, SKF 525-A; - -0 , SKF 330I-A.

Fig. 4. Phytophthora cactorum. Growth (as dry weight after 14 days) in media with various concentrations of hypocholesteremic compounds. $\bigcirc-\mathrm{O}$, SKF 2374; $\triangle-\cdot \triangle \triangle$, SKF I6467-A; -0 , SKF 330I-A.

than in definite rings. At $100 \mathrm{mg}$./1. and higher concentrations the number of perithecia was decreased though some were found even at $200 \mathrm{mg}$./1., but a great many tiny perithecial initials were produced, especially in the region corresponding to the definite ring of perithecia formed at lower concentrations.

Compounds $S K F$ 2314, $S K F$ 7732- $A_{3}$ and $S K F$ 7997- $A_{3}$. These compounds had little effect, growth rate being reduced by only $30 \%$ at a concentration of SKF 23 I4 of $320 \mathrm{mg} . / \mathrm{l}$. (Fig. 3), and by less than this with $7732-\mathrm{A}_{3}$ and $7993-\mathrm{A}_{3}$. There were no effects on perithecial production at this concentration with any of the three.

Compound $A Y$ 9944. At concentrations of this compound above $10 \mathrm{mg}$./l. a curious puffing of the margin of the colony took place when growth rate was slowing down 
(Pl. I, fig. 6). Sometimes a single hypha extended for some distance through the medium and then produced a dense mass of much branched mycelium. The effects on perithecial production were strikingly different from SKF $330 \mathrm{I}-\mathrm{A}$ etc., in that at concentrations of the drug which partially inhibited vegetative growth there was no increase in the numbers of perithecia produced. Indeed, perithecia were very few at any concentrations where the mycelium did not rapidly fill the Petri dish; e.g. at AY $994425 \mathrm{mg}$./1. the initial growth rate was reduced by $20 \%$ but no perithecia were formed (Pl. I, fig. 6). In such colonies the central part was darkly pigmented, though the edge was often pale.

Table 2. Sordaria fimicola. Effect of fatty acids etc. annulling growth inhibition by SKF 330I-A

\begin{tabular}{|c|c|c|c|c|}
\hline \multirow{2}{*}{$\begin{array}{l}\text { Substance } \\
\text { added }\end{array}$} & \multirow{2}{*}{$\begin{array}{c}\text { Concentration } \\
\mathrm{mg} . / \mathrm{l} \text {. }\end{array}$} & \multicolumn{3}{|c|}{ Concentration of SKF 330I-A (mg./1.) } \\
\hline & & 0 & 50 & 100 \\
\hline None & - & $\begin{array}{c}29 \cdot 7 \pm 0 \cdot 71 \\
100\end{array}$ & $5.5 \pm 0.22$ & ${ }_{13}^{4.0 \pm 0.52}$ \\
\hline Oleic acid & $\begin{array}{l}200 \\
800\end{array}$ & $\begin{array}{c}25.7 \pm 0.67 \\
87 \\
27 \cdot 8 \pm 0.31 \\
94\end{array}$ & $\begin{array}{c}20 \cdot 7 \pm 2 \cdot 37 \\
70 \\
26 \cdot 7 \pm 0 \cdot 49 \\
90\end{array}$ & $\begin{array}{c}6 \cdot 7 \pm 0 \cdot 71 \\
22 \\
19 \cdot 7 \frac{2}{66} \cdot 88\end{array}$ \\
\hline Linoleic acid & $\begin{array}{l}200 \\
800\end{array}$ & $\begin{array}{c}24 \cdot 3 \pm 0 \cdot 67 \\
82 \\
I 3 \cdot 5 \pm \mathrm{I} \cdot 38 \\
46\end{array}$ & $\begin{array}{c}21 \cdot 3 \pm 1 \cdot 20 \\
72 \\
16 \cdot 2 \pm I \cdot 33 \\
54\end{array}$ & $\begin{array}{c}I 0 \cdot 7 \pm I \cdot 3 I \\
36 \\
I 3 \cdot 3 \pm I \cdot 4 I \\
45\end{array}$ \\
\hline Methyl linoleate & $\begin{array}{l}200 \\
800\end{array}$ & $\begin{array}{c}28.2 \pm 0.17 \\
95 \\
25.8 \pm 0.60 \\
87\end{array}$ & $\begin{array}{c}12 \cdot 3 \pm 0.49 \\
42 \\
\text { II } 8 \pm 0.65 \\
40\end{array}$ & $\begin{array}{c}5 \cdot 7 \pm 1 \cdot 33 \\
19 \\
7 \cdot 7 \pm 0 \cdot 88 \\
26\end{array}$ \\
\hline Elaidic acid & $\begin{array}{l}200 \\
800\end{array}$ & $\begin{array}{c}31 \cdot 7 \pm 0.56 \\
107 \\
30 \cdot 8 \pm 0 \cdot 70 \\
104\end{array}$ & $\begin{array}{c}7 \cdot 0 \pm 0.26 \\
24 \\
10.5 \pm 1 \cdot 02 \\
35\end{array}$ & $\begin{array}{c}3.8 \pm 0.31 \\
13 \\
4.3 \pm 0.42 \\
15\end{array}$ \\
\hline Stearic acid & $\begin{array}{l}200 \\
800\end{array}$ & $\begin{array}{c}27 \cdot 0 \pm I \cdot 00 \\
91 \\
27 \cdot 3 \pm 0 \cdot 92 \\
92\end{array}$ & $\begin{array}{c}7 \cdot 8 \pm I \cdot 27 \\
26 \\
8 \cdot 2 \pm 0 \cdot 57 \\
27\end{array}$ & $\begin{array}{c}2.8 \pm 0.31 \\
10 \\
3.8 \pm 0.54 \\
13\end{array}$ \\
\hline Cholesterol & 100 & $26 \cdot 0 \pm 0 \cdot 94$ & $\frac{6 \cdot 0 \pm 0.48}{20}$ & $3 \cdot 3 \pm 0.33$ \\
\hline
\end{tabular}

Annullment of the effects of compounds SKF 330r-A and AY 9944 on growth of Sordaria fimicola. As shown in Tables 2 and 3, cholesterol was ineffective in annulling the effects of compounds SKF $3301-A$ and AY 9944 on hyphal growth rate, but oleic acid (cis-octadec-9-enoic acid) was highly effective. Linoleic acid (octadec-9, I2-dienoic acid) was rather toxic, but when allowance was made for its toxicity it was evident that it could also annul the effects of both compounds. Methyl lineolate and elaidic acid (trans-octadec-9-enoic acid) were less effective. Elaidic acid appeared to be about half as effective as oleic acid (compare Kodicek \& Worden, 1946). Stearic acid (octadecanoic acid) was ineffective. Ergosterol was also ineffective. These results are based on measurements of colony diameter over periods of up to $24 \mathrm{hr}$ during the initial phase of 
more rapid growth. Provided an adequate amount of unsaturated fatty acid was supplied, growth in drug + media continued uninterruptedly to the edge of the dish.

The effects of oleic acid and cholesterol on perithecial production in media-containing hypocholesteremic compounds were studied; but first, the effects of oleic acid and cholesterol alone must be mentioned. In media to which only oleic acid was added the surface hyphae had a curious waviness (Pl. I, fig. 7). There were cushion-like

Table 3. Sordar ia fimicola. Effect of fatty acids etc. annulling growth inhibition by $A Y 9944$

Increase in colony diameter during a $10 \frac{1}{2} \mathrm{hr}$ period com mencing $37 \mathrm{hr}$ after inoculation, relative to the control value.

\begin{tabular}{|c|c|c|c|c|}
\hline \multirow{2}{*}{ Substance added } & \multirow{2}{*}{$\begin{array}{l}\text { Concentration } \\
(\mathrm{mg} . / 1 .)\end{array}$} & \multicolumn{3}{|c|}{ Concentration of AY 9944 (mg./1.) } \\
\hline & & 0 & 100 & 300 \\
\hline None & - & 100 & 73 & 7 \\
\hline Oleic acid & $\begin{array}{r}400 \\
1200\end{array}$ & $\begin{array}{l}97 \\
94\end{array}$ & $\begin{array}{l}86 \\
92\end{array}$ & $\begin{array}{l}25 \\
70\end{array}$ \\
\hline Linoleic acid & $\begin{array}{r}400 \\
\text { I } 200\end{array}$ & $\begin{array}{l}4 I \\
28\end{array}$ & $\begin{array}{l}50 \\
35\end{array}$ & $\begin{array}{l}49 \\
39\end{array}$ \\
\hline Methyl lineolate & $\begin{array}{r}400 \\
1200\end{array}$ & $\begin{array}{l}81 \\
75\end{array}$ & $\begin{array}{l}6 \mathrm{I} \\
4 \mathrm{I}\end{array}$ & $\begin{array}{l}8 \\
2\end{array}$ \\
\hline Elaidic acid & $\begin{array}{r}400 \\
1200\end{array}$ & $\begin{array}{l}86 \\
89\end{array}$ & $\begin{array}{l}65 \\
75\end{array}$ & $\begin{array}{l}28 \\
42\end{array}$ \\
\hline Stearic acid & 1200 & 86 & 76 & 5 \\
\hline Cholesterol & $\begin{array}{r}400 \\
1200\end{array}$ & $\begin{array}{l}86 \\
85\end{array}$ & $\begin{array}{l}50 \\
44\end{array}$ & $\begin{array}{l}\text { I } \\
8\end{array}$ \\
\hline
\end{tabular}

Table 4. Sordaria fimicola. Effect of SKF 330I-A, oleic acid and cholesterol on numbers of perithecia in 7-day-old cultures

Mean count from four sectors in each of four Petri dishes.

Concentration of SKF 3301-A (mg.1.)...

Concentration of oleic acid (mg./1.)...

Concentration of cholesterol (mg./l.)

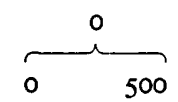

$134 \quad 127$

$138 \quad$ II9

100
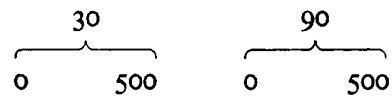

II9 $55^{*}$

$\begin{array}{rr}72 * & 7 \\ 55^{*} & 99\end{array}$

06

* After a further 5 days with continued growth of the colonies these counts increased to 180 and 156 respectively. With other treatments the growth of the colonies was completed in 7 days.

\section{Analysis of variance}

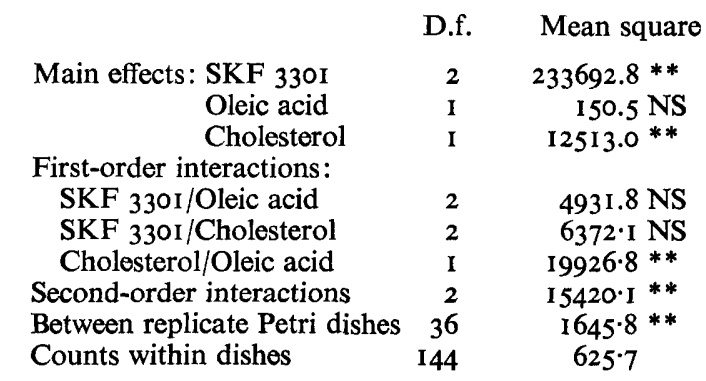

** Significant at I \% lovel; NS, not significant. 
aggregates of hyphae, darkly pigmented, and raised above the surface of the agar, and these sometimes bore numerous perithecia; but in the main the surface of the culture was bare of perithecia, these being numerous only at the extreme edge of the dish against the glass. The effect of cholesterol alone was slight, but its addition to media with SKF $330 \mathrm{I}-\mathrm{A} 30$ or $35 \mathrm{mg}$./1. (no oleic acid) made the zonation of perithecia less pronounced; also perithecial production was somewhat accelerated in the presence of cholesterol, the perithecia being formed outside the first ring before there were any outside it in the medium without cholesterol.

\section{Table 5. Sordaria fimicola. Effect of $A Y 9944$, oleic acid and cholesterol on numbers of perithecia in II-day-old cultures}

Mean count from two sectors in each of 6 Petri dishes.

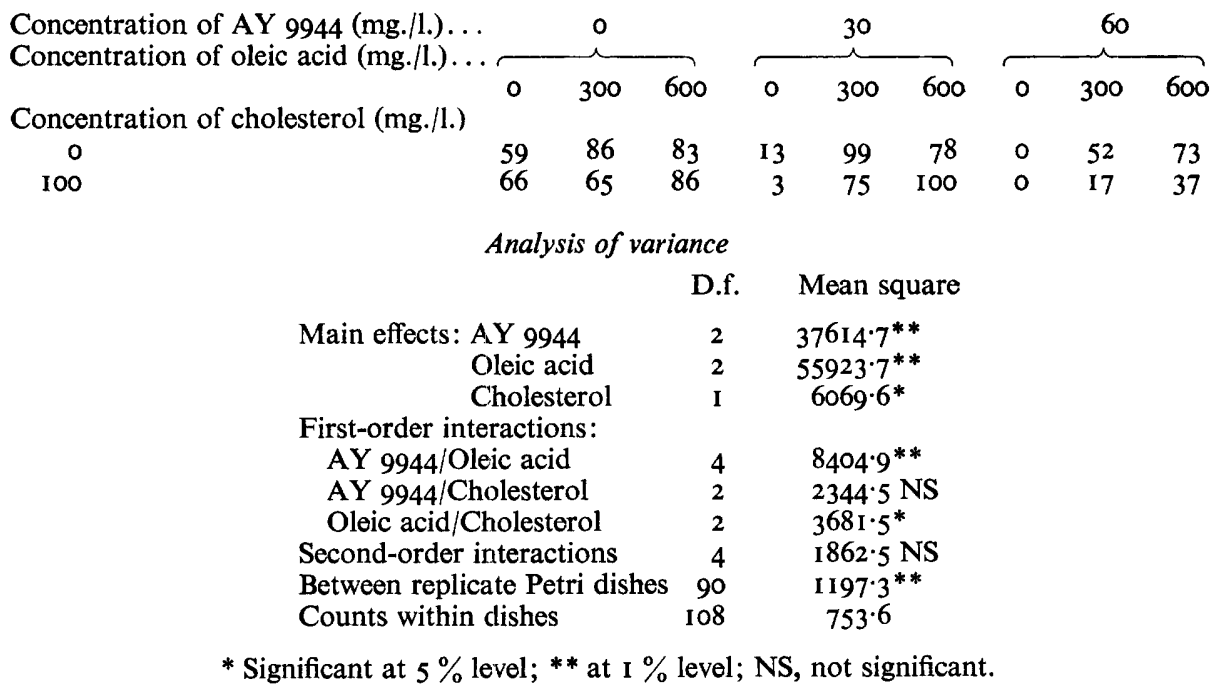

Results for oleic acid and cholesterol with SKF 330I-A are shown in Table 4. The addition of oleic acid alone to media with SKF 330I-A resulted in few perithecia (P1. I, fig. 8); the number was increased if cholesterol was added (Pl. I, fig. 9), the increase being significant as shown by the second-order interaction in Table 4 .

The results with compound AY 9944 were however different. In six experiments there was either no increase in the numbers of perithecia with the addition of cholesterol to the medium with AY 9944 and oleic acid (Table 5), or an increase which was comparable with that observed in the controls without AY 9944. The second-order interactions, which were significant in the SKF 330I-A experiments, were not significant. In Table 5 there is a significant main effect of cholesterol, but this is due to the decrease in the numbers of perithecia in the treatments with cholesterol.

\section{Observations on Phytophthora cactorum}

Compounds SKF 23I4, 525-A, 330I-A, I6467-A, and AY 9944 all inhibited the growth of Phytophthora cactorum, the effective concentrations being less than for Sordaria fimicola (Fig. 4; cf. Fig. 3). SKF 7732- $\mathrm{A}_{3}$ and $7997-\mathrm{A}_{3}$ were also inhibitory at low concentrations, but adaptation to them occurred, as shown in Fig. 5. When 
mycelium growing on SKF 7997- $\mathrm{A}_{3}$ was transferred to fresh drug-containing medium (4 $\mathrm{mm}$. disc inoculum cut from the hyphal front), it did not immediately grow, but did so after a lag period similar to that observed in the first place. The lag period was the same on both freshly made medium and medium kept at $24^{\circ}$ for 14 days.

The effectiveness of oleic acid and cholesterol in annulling the inhibition of growth due to compounds SKF 330I-A and AY 9944 has been examined (Table 6). In the absence of drug, the effect of oleic acid alone was to give extremely rapid growth of the hyphae, but the colony was much less dense than on basal medium. Addition of

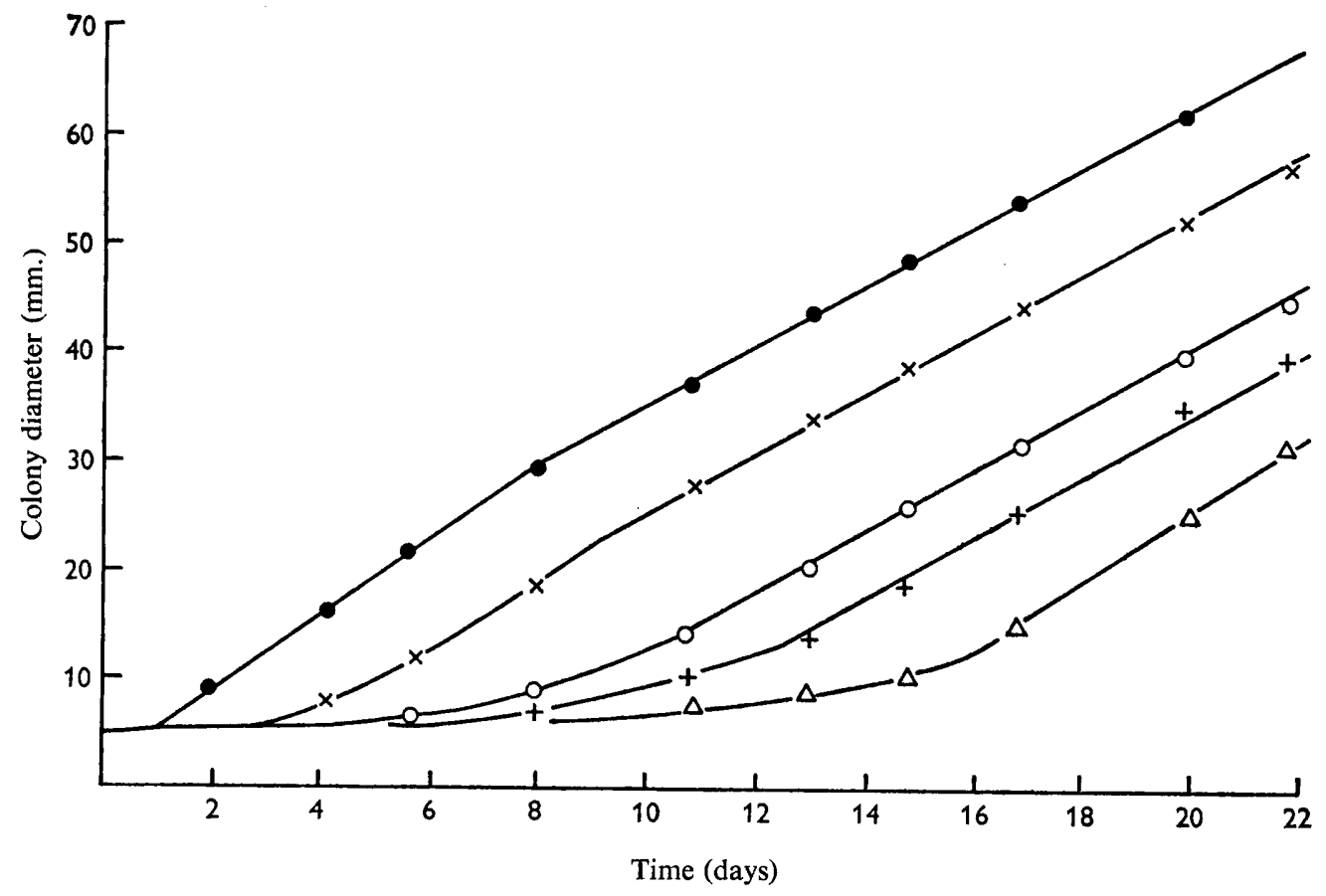

Fig. 5. Phytophthora cactorum. Growth in medium with various concentrations of SKF 7997-A . $-\bullet$, o mg./l.; $\times-\times$, I mg./1.; O-O, 2 mg./I.; +-+, 3 mg./l.; $\triangle-\triangle$, $4 \mathrm{mg} . / 1$.

cholesterol with the oleic acid increased colony density. On media with SKF 330I-A or AY 9944 and oleic acid, hyphae grew out from the inoculum, but the growth was exceedingly sparse. However, the addition of cholesterol as well restored the appearance of the colony virtually to normal. Cholesterol by itself seemed to have some effect except at the higher concentration of SKF 330I-A. In the treatments marked with an asterisk in Table 6 there was much variation from dish to dish, in some cases growth hardly starting from the inoculum while in others a large very dense growth occurred.

The fact that cholesterol had to be added with the oleic acid to annul the effects of the inhibitors might be attributed to a need to detoxify the oleic acid. Unsaturated fatty acids are toxic to lactobacilli, but this toxicity can be annulled by a number of compounds, notably sterols (Kodicek, 1949) and Tween 40 (Williams, Broquist \& Snell, 1947). Hendrix, Norman \& Apple (1966) considered oleic acid to be toxic to 
Phytophthora, but found the toxicity could be annulled by cholesterol and tocopherol. Tween 40 did not appear to be an effective replacement for cholesterol in my experiments.

\section{Table 6. Phytophthora cactorum. Effect of oleic acid and cholestero on growth in media with SKF 330I-A or AY 9944}

Diameter (mm.) (upper figure) and dry wt (mg.) (middle figure) and density (lowest figure) after 9 days incubation. The inoculum was of diameter $5 \mathrm{~mm}$. and dry wt approx. $0.8 \mathrm{mg}$. Means of 6 values. The 6 mycelia of each treatment were weighed together. Density = $\left(100 \times\right.$ dry wt)/(diameter $\left.{ }^{2}\right)$.

Concentration of oleic acid (mg./l.)... o

Concentration of

cholesterol (mg./l.). . .

No inhibitor

SKF 33OI-A

$24 \mathrm{mg}$. $/ 1$.

$88 \mathrm{mg} . / 1$.

AY 9944
$24 \mathrm{mg} . / 1$.

$88 \mathrm{mg} . / 1$.

$\begin{array}{cc}0 & 35 \\ 31 \cdot 7 \pm 0.13 & 35.5 \pm 0.92 \\ 17 \cdot 0 & 22 \cdot 7 \\ 1.69 & 1 \cdot 80\end{array}$

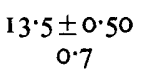

$-$

$$
\begin{gathered}
7 \cdot 8 \pm 0 \cdot 78 \\
0.2 \\
-
\end{gathered}
$$

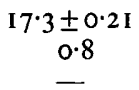

$15 \cdot 3 \pm 2 \cdot 14$

0.7

$$
\begin{gathered}
12 \cdot 5 \pm 2 \cdot 4 \mathrm{I}^{*} \\
4 \cdot 7 \\
3 \cdot 01 \\
6 \cdot 3 \pm 0.67 \\
0.8
\end{gathered}
$$$$
-
$$

$$
\begin{gathered}
19 \cdot 5 \pm 4 \cdot 14 * \\
12 \cdot 9 \\
3 \cdot 16 \\
12 \cdot 8 \pm \mathrm{I} \cdot 70 \\
4 \cdot 2 \\
2 \cdot 56
\end{gathered}
$$

* Note high variance.

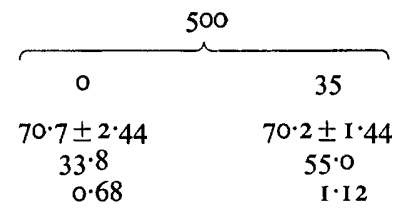

$$
\begin{gathered}
59 \cdot 2 \pm 1 \cdot 50 \\
3 \cdot 5 \\
0 \cdot 10 \\
54 \cdot 5 \pm I \cdot 33 \\
4 \cdot 7 \\
0 \cdot 16
\end{gathered}
$$
$62 \cdot 3 \pm I \cdot 3 I$
$4 \mathrm{I} \cdot 7$
$\mathrm{I} \cdot 07$

$34 \cdot 7 \pm 6 \cdot 36^{*}$

$18 \cdot 0$

I. 50

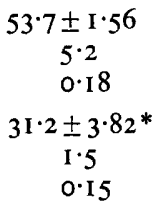
$62 \cdot 8 \pm 2 \cdot 17$
$42 \cdot 7$
$\mathrm{I} \cdot 08$

$29 \cdot 8 \pm 5 \cdot 82 *$

$14 \cdot 0$

$\mathrm{I} \cdot 58$

\section{DISCUSSION}

The compounds SKF 330I-A and I6467-A have in common the two groups $\left(\mathrm{C}_{6} \mathrm{H}_{5}\right)_{2}\left(\mathrm{C}_{3} \mathrm{H}_{7}\right)$ - and - $\left(\mathrm{CH}_{2}\right)_{2} \mathrm{~N}\left(\mathrm{CH}_{3}\right)_{2}$, and SKF 525-A has $\left(\mathrm{C}_{6} \mathrm{H}_{5}\right)_{2}\left(\mathrm{C}_{3} \mathrm{H}_{7}\right)-$ and $-\left(\mathrm{CH}_{2}\right)_{2} \mathrm{~N}\left(\mathrm{C}_{2} \mathrm{H}_{5}\right)_{2}$; the central parts of the molecules are however different (Fig. I). All three compounds inhibited the growth of Sordaria fimicola, but their effects were characteristic. SKF 330I-A was effective at lower concentrations than I6467-A, but with both a marked change of growth rate occurred when the mycelium had grown part of the way across the Petri dish. Only SKF 330I-A produced the marked zonation of perithecia during the latter period of slower growth; with SKF I6467-A there were many more abortive perithecia. Abortive perithecia were also numerous with SKF 525-A, and this compound produced marked thinning of the edge of the colony. Neither of the compounds SKF 23I4, which has only the $\left(\mathrm{C}_{6} \mathrm{H}_{5}\right)_{2}\left(\mathrm{C}_{3} \mathrm{H}_{7}\right)$ - group, nor SKF 7997- $\mathrm{A}_{3}$, which has only - $\left(\mathrm{CH}_{2}\right)_{2} \mathrm{~N}\left(\mathrm{C}_{2} \mathrm{H}_{5}\right)_{2}$, was inhibitory. All these compounds were inhibitory to Phytophthora cactorum, the toxic concentrations being lower than for $S$. fimicola. The effects of these compounds on several bacteria and fungi were described by Aaronson \& Fulco (1968) and on the ciliate Ochromonas danica by Aaronson (1966). 
The inhibition of vegetative growth of Sordaria fimicola by the compounds SKF 330I-A and AY 9944 was annulled by unsaturated fatty acids but not by sterols. It is possible that the sterols, being present as crystals dispersed through the agar, could not be taken up by this fungus, although sterols so presented to Phytophthora cactorum are effective. Nevertheless, while the effects of two other compounds which inhibit sterol synthesis, triparanol and benzmalecene, on growth of various ciliates and flagellates could be annulled by both sterols and unsaturated fatty acids (Aaronson, Bensky, Shrifrine \& Baker, I962; Holz, Erwin, Rosenbaum \& Aaronson, 1962), the delay in division induced by triparanol in synchronous cultures of Tetrahymena pyriformis could be prevented by oleic acid and not by sterols (Holz et al. 1962). Again, oleic acid but not sterols annulled the effect of SKF 525-A and 330I-A on Ochromonas danica (Aaronson, 1966). Aaronson $(1964,1965)$ found that the effects of triparanol and benzmalecene on several micro-organisms were more effectively annulled by oleic acid than by ergosterol or squalene (though not in all cases; Aaronson \& Fulco, 1968); saturated acids were ineffective. These and my results are difficult to explain unless the compounds inhibit processes other than sterol synthesis. The fact that growth of Phytophthora cactorum is inhibited by hypocholesteremic compounds is significant, as Phytophthora appears not to synthesize sterols. Compound SKF 525-A is in fact known to affect other processes in mammalian systems; the hydrolysis of procaine, for example, is inhibited competitively, and demethylation of $o$-anisole non-competitively (Netter, 1962).

Although the addition of oleic acid to medium with compounds SKF 330I-A or AY 9944 resulted in vigorous hyphal growth of Sordaria, it did not lead to normal reproductive competence. Perithecia were few and irregularly distributed, and the mycelium developed much brown pigment. It would appear that oleic acid repairs the lesions induced in processes essential for vegetative growth more effectively than in those required for reproduction. It may be significant that the addition of cholesterol to media with intermediate amounts of SKF $330 \mathrm{I}-\mathrm{A}$ ( 30 to $35 \mathrm{mg}$./l.) speeded up perithecium formation and decreased the definition of zonation, but the effect was slight. More definitely, the addition of cholesterol to media with oleic acid and SKF 330I-A improved reproductive competence. This was not observed with AY 9944, but the latter compound was manifestly different in its action from the SKF compounds; particularly, it did not lead to an increase in perithecial production when present in the medium at concentrations sub-inhibitory to vegetative growth. That sterols are involved in the effects of SKF 330I-A and similar compounds on reproductive phases was strikingly shown by the work of Nelson, Huisingh \& Webster (1967) with the heterothallic ascomycete Cochliobolus carbonum. They applied SKF 330I-A to partly grown cultures at various times after mating, and found that perithecial development was inhibited; this inhibition was annulled by the addition of various sterols.

I am indebted to Messrs Smith, Kline and French Laboratories, Welwyn Garden City, Hertfordshire, and Philadelphia, Pennsylvania, and to Imperial Chemical Industries, Pharmaceuticals Division, Alderley Park, Macclesfield, Cheshire, for supplying the hypocholesteremic drugs. I also wish to thank Professor P. W. Brian, F.R.S., for his interest in this work and for many suggestions. 


\section{REFERENCES}

Aaronson, S. (1964). A role for a sterol and a sterol precursor in the bacterium Rhodopseudomonas palustris. J. gen. Microbiol. 37, 225.

AARONSON, S. (1965). Inhibition of microbial multiplication by hypocholesteraemic compounds. J. gen. Microbiol. 39, 367.

AARONSON, S. (1966). Study of the cellular action of drugs with protozoa. III. Comparison of the effect of SKF 525-A and related compounds on the multiplication of Ochromonas danica. Biochem. Pharmac. 15, I24I.

AARONSON, S. \& Fulco, L. (I968). Effect of hypocholesteremic compounds on bacterial multiplication. J. gen. Microbiol. 50, 271.

Aaronson, S., Bensky, B., Shrifrine, M. \& Baker, H. (1962). Effect of hypocholesteremic agents on protozoa. Proc. Soc. exp. Biol. Med. ro9, 130.

BonNer, J., HeftmanN, E. \& ZeevaART, J. A. D. (1963). Suppression of floral induction by inhibitors of steroid biosynthesis. Pl. Physiol., Lancaster 38, 8I.

Chappel, C., Dubuc, J., Dvornik, D., Givner, M., Humber, L., Kraml, M., Votth, K. \& Gaudry, R. (1964). An inhibitor of cholesterol biosynthesis. Nature, Lond. $201,498$.

CheE, K.-H. \& TuRner, N. A. (1965). A steroid factor in pea (Pisum sativum L.) influencing growth and sporulation of Phytophthora cinnamomi Rands. N.Z. Jl agric. Res. 8, I04.

Elliott, C. G., Hendrie, M. R., KNights, B. A. \& PARKer, W. (1964). A steroid growth factor requirement in a fungus. Nature, Lond. $203,427$.

Haskins, R. H., Tulloch, A. P. \& Micetich, R. G. (1964). Steroids and the stimulation of sexual reproduction of a species of Pythium. Can. J. Microbiol. 10, 187.

HeNDrIX, J. W. (1964). Sterol induction of reproduction and stimulation of growth of Pythium and Phytophthora. Science, N.Y. r44, ro28.

HeNDRIX, J. W. (1965). Influence of sterols on growth and reproduction of Pythium and Phytophthora, spp. Phytopathology 55, 790.

HendRIX, J. W. (1966). Inability of Pythium aphanidermatum and Phytophthora palmivora to incorporate acetate into digitonin-precipitable sterols. Mycologia 58, 307.

Hendrix, J. W., Norman, C. \& Apple, J. L. (1966). Chemical and physical factors influencing growth of Phytophthora parasitica var. nicotianae on vegetable oils. Physiologia Pl. 19, 159.

Holmes, W. L. \& BENTz, J. D. (1960). Inhibition of cholesterol biosynthesis in vitro by $\beta$-diethylaminoethyldiphenylpropyl acetate hydrochloride (SKF 525-A). J. biol. Chem. 235, 3118.

Holmes, W. L. \& Di Tullio, N. W. (1962). Inhibitors of cholesterol biosynthesis which act at or beyond the mevalonic acid stage. Am. J. clin. Nutr. 10, 310.

Holz, G. G., Erwin, J., Rosenbaum, N. \& Aaronson, S. (1962). Triparanol inhibition of Tetrahymena and its prevention by lipids. Archs Biochem. Biophys. 98, 312.

HORLICK, J. (1966). Effect of a new inhibitor of cholesterol biosynthesis (AY 9944) on serum and tissue sterols in the rat. J. Lipid Res. 7, 116.

KoDICEK, E. (1949). The effect of unsaturated fatty acids on Gram-positive bacteria. Symp. Soc. exp. Biol. 3, 217.

KoDICEK, E. \& WoRDEN, A. N. (I946). Effect of unsaturated fatty acids on the acid production of Lactobacillus helveticus. Nature, Lond. 157, 587.

Leal, J. A., Friend, J. \& Holliday, P. (I964). A factor controlling sexual reproduction in Phytophthora. Nature, Lond. 203, 545.

Nelson, R. R., Huisingh, D. \& Webster, R. K. (1967). Sexual differentiation in Cochliobolus carbonum as influenced by inhibition and repair of steroid biosynthesis. Phytopathology 57, 1081.

NetTer, K. J. (1962). Drugs as inhibitors of drug metabolism. Proc. First Int. pharmac. Mtg. 6, 213.

SChlosser, E. \& GotTlieb, D. (1966). Sterols and the sensitivity of Pythium species to filipin. J. Bact 9I, 1080 .

TIMNICK, M. B., LILLY, V. G. \& BARNETT, H. L. (195I). The effect of nutrition on the sporulation of Melanconium fuligineum in culture. Mycologia 43, 625 .

Williams, W. L., BRoQUIST, H. P. \& SNeLL, E. E. (1947). Oleic acid and related compounds as growth factors for lactic acid bacteria. J. biol. Chem. 170, 619 . 
Journal of General Microbiology, Vol. 56, No. 3

Plate I
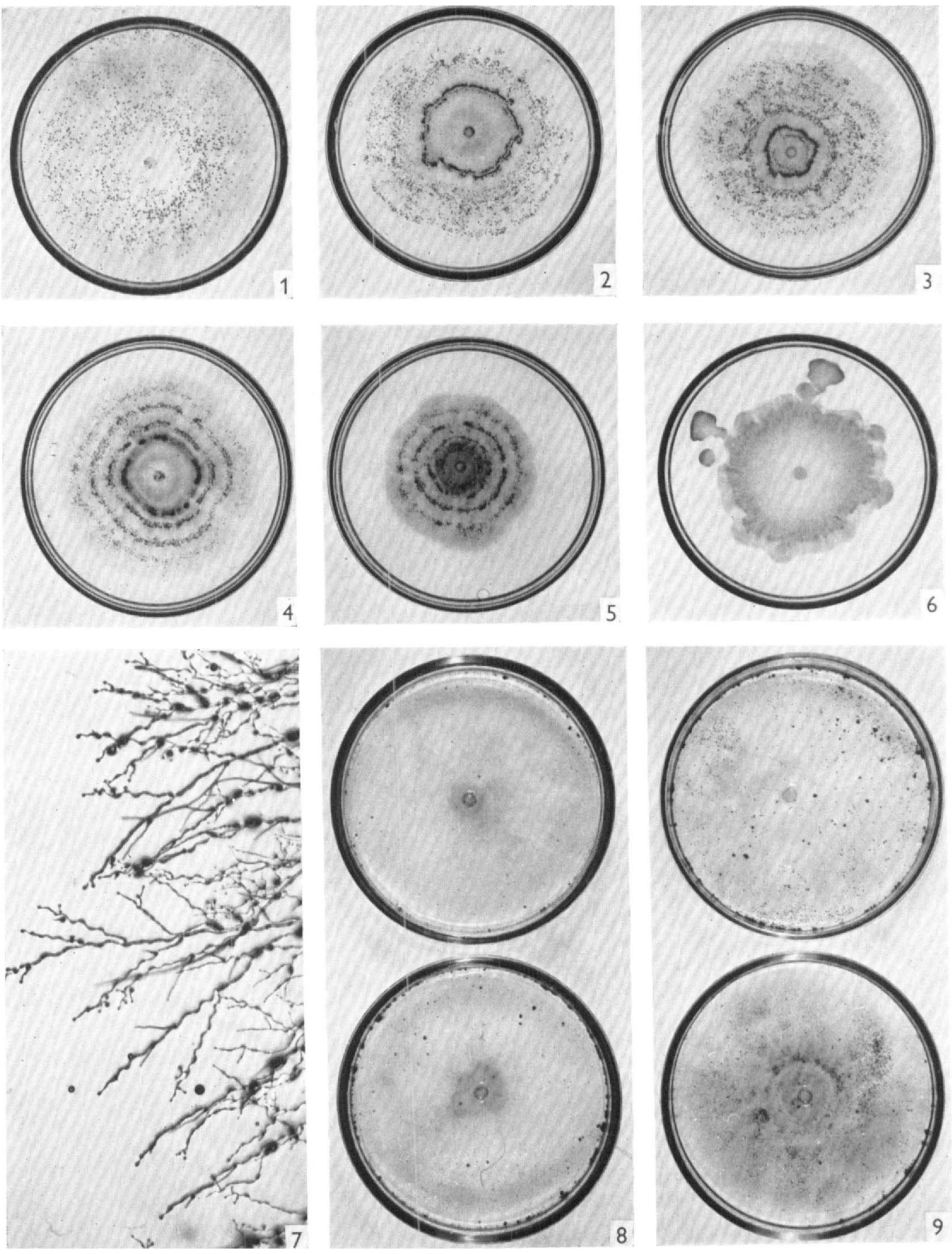

C. G. ELLIOTTT

(Facing p. 343) 


\section{EXPLANATION OF PLATE}

Sordaria fimicola

Fig. I. Control culture on drug-free medium.

Fig. 2. SKF 330I-A, $20 \mathrm{mg} . / 1$.

Fig. 3. SKF 330I-A, $30 \mathrm{mg} . / 1$.

Fig. 4. SKF 330I-A, $40 \mathrm{mg} . / 1$.

Fig. 5. SKF 330I-A, $50 \mathrm{mg} . / \mathrm{l}$.

Fig. 6. AY 9944, $25 \mathrm{mg}$./l.

Fig. 7. Hyphae on medium with oleic acid.

Fig. 8. SKF 3301-A, $70 \mathrm{mg} . / 1 .+$ oleic acid, $500 \mathrm{mg} . / \mathrm{l}$.

Fig. 9. SKF 330I-A, $70 \mathrm{mg} . / 1 .+$ oleic acid, $500 \mathrm{mg} . / 1 .+$ cholesterol, $100 \mathrm{mg} . / 1$. 